AperTO - Archivio Istituzionale Open Access dell'Università di Torino

\title{
Root plasticity of Nicotiana tabacum in response to phosphorus starvation
}

\section{This is the author's manuscript}

Original Citation:

Availability:

This version is available http://hdl.handle.net/2318/1505322

since 2018-07-11T12:21:05Z

Published version:

DOI:10.1080/11263504.2014.986245

Terms of use:

Open Access

Anyone can freely access the full text of works made available as "Open Access". Works made available under a Creative Commons license can be used according to the terms and conditions of said license. Use of all other works requires consent of the right holder (author or publisher) if not exempted from copyright protection by the applicable law. 
This is the author's final version of the contribution published as:

Maria, Foti; Stefania, Dho; Fusconi, A. Root plasticity of Nicotiana tabacum in response to phosphorus starvation. PLANT BIOSYSTEMS. None pp: 1-7. DOI: $10.1080 / 11263504.2014 .986245$

The publisher's version is available at:

http://www.tandfonline.com/doi/full/10.1080/11263504.2014.986245

When citing, please refer to the published version.

Link to this full text:

http://hdl.handle.net/2318/1505322 


\section{Root plasticity of Nicotiana tabacum in response to phosphorus starvation}

Maria Foti, Stefania Dho, Anna Fusconi1.

Department of Life Sciences and Systems Biology, Università di Torino, Viale Mattioli 25,

10125, Torino, Italy.

1 Corresponding author:

Tel.: +39011 6705968;

fax: +390116705962 .

E-mail address: anna.fusconi@ unito.it (A. Fusconi). 


\title{
Root plasticity of Nicotiana tabacum in response to phosphorus starvation
}

\begin{abstract}
Tobacco plants under low phosphate exhibited increased total and tap root length, as a result of higher apex activity, but decreased root branching in comparison to the plants grown with high-Pi. The possible mechanisms and significance of these alterations, which differed from those typical of stress-induced morphogenetic responses, are discussed.
\end{abstract}

Keywords: root system architecture, root apices, phosphate, cadmium, stress, Arabidopsis, auxin, arbuscular mycorrhizae.

\section{Introduction}

Plant development is highly variable and strongly influenced by environmental signals. In particular the root system is highly plastic, and this plasticity allows the plant to optimize the acquisition of the resources from the soil (Malamy 2005; Barlow 2010) or to cope with stressful conditions (Potters et al. 2007; 2009). Root architecture allows plants to compete effectively for resources and survive to nutrient starvation, and is thus central to reach optimal plant growth and yield (Malamy 2005; Den Herder et al. 2010). Among soil nutrients which significantly impact plant growth and health, phosphorus is one of the most important. However, it is largely unavailable for plant uptake (Vance et al. 2003). Plants respond to phosphate $(\mathrm{Pi})$ starvation by altering their biochemistry, physiology and morphology in order to conserve $\mathrm{Pi}$, to enhance $\mathrm{Pi}$ acquisition and to extend the exploration of the soil (Vance et al. 2003; Hammond and White 2008). A common response of plants grown in Pi limiting conditions is an increased rootto-shoot biomass ratio in relation to the non-starved counterparts (Ramaekers et al. 2010). In addition, plants may modify root system architecture. Some of them, such as Arabidopsis thaliana (López-Bucio et al. 2002; Sánchez-Calderón et al. 2005) and some Brassica cultivars (Akthar et al. 2009), respond to Pi-shortage by producing a shorter and more branched primary root. In other species, instead, primary (or adventitious) root length is increased or is unchanged by low Pi conditions; furthermore, unlike Arabidopsis, some plants show a lower degree of branching than those grown with higher Pi levels (reviewed by Fusconi 2014). However, despite the abundant literature dealing with Pi effect upon root morphogenesis, there is still a considerable incoherence often resulting from differences in experimental designs and/or morphological parameters considered. 
Chronic stresses also, including metal toxicity, have shown to affect root morphogenesis even when they enable plants to survive and grow (Potters et al. 2007; 2009). These stresses induce a specific "Stress-Induced Morphogenetic Response" (SIMR, Potters et al. 2007) of the whole plant, which consists in an active and orchestrated redistribution of growth, rather than in a simple cessation of it, as a consequence of toxicity. In the roots, SIMRs lead to primary roots shorter than those of the non-stressed controls, following a block of meristem activity and inhibition of cell elongation, and to increased branching (Potters et al. 2007). In order to extend our knowledge on the influence of Pi nutrition on root system architecture, we studied the effects of Pi availability on tobacco (Nicotiana tabacum) plants using a culture method similar to those commonly used for Arabidopsis. We chose tobacco because it is a model plant of agronomic interest and easily cultivable in Petri plates for a relatively long period, whose root morphogenesis in responses to Pi availability is still little known. In addition, we analyzed the effects on root morphogenesis of cadmium (Cd), a heavy metal widespread in the environment, non-essential but readily taken up by the roots, whose toxicity on plants (Sanità di Toppi and Gabbrielli 1999; Hattab et al. 2009; Garg and Bhandari 2013) and effects on root morphogenesis (Hu et al. 2013) are well documented. Results obtained in tobacco are discussed by comparison with A. thaliana, in consideration of the huge amount of data available for this plant on the regulation of root morphogenesis under low Pi condition and other stresses, including Cd toxicity.

\section{Materials and methods}

\section{Plant material and growth conditions}

Seeds of Nicotiana tabacum L. var. Petit Avana SR-1 obtained from A.R.S. (Agricultural Research Service, USA) were surface-sterilized for $5 \mathrm{~min}$. in $1 \%$ sodium hypochlorite solution and sown in square Petri plates $(120 \times 120 \times 17 \mathrm{~mm}$, four seeds per plate) containing half-strength Murashige and Skoog ( $1 / 2$ MS) media deprived of $\mathrm{Pi}(\mathrm{P}$ - treatment) or with $1 \mathrm{mM} \mathrm{Pi}$ as KH2PO4/K2HPO4 (P+ treatment). The growth media were solidified with 1\% agar (A-1296, SigmaAldrich, containing about $20 \mu \mathrm{M} \mathrm{P}$ ). The strength of the MS medium and Pi concentrations were chosen on the basis of preliminary experiments. The plates were placed almost vertically in a growth chamber, without shading the roots, under controlled conditions (16/8h light/dark photoperiod, $25 / 22 \pm 1^{\circ} \mathrm{C}$ thermoperiod, $150 \mu \mathrm{mol} \cdot \mathrm{m}-2 \mathrm{sec}-1)$, to allow root growth along the surface of the agar. 


\section{Ponderal and morphometric analyses}

After 28 days from germination, the dry weights of the shoots and roots of 15 plantlets were determined, and the root-to-shoot ratio was calculated. Images of the root system of 12 seedlings per treatment were recorded weekly up to 28 days from germination, by placing the Petri dishes, with a metric reference, directly onto a scanner Epson Perfection 1240U (resolution: 400dpi, 800dpi for root apex magnifications). The leaves were detached and scanned. The numbers of $1 \mathrm{st}$ order lateral roots and leaves were counted. The length of the roots of each order and the leaf area were measured using the image analysis software Lucia G (LIM, Praha, CZ); the degree of root branching (i.e. the number of lateral roots per length of the tap root) was calculated.

\section{Cortical cell length, root apex structure and activity}

i) The length of 100 mature cortical cells per treatment of the tap roots was determined, with an ocular micrometer scale, on freehand longitudinal sections taken immediately above the differentiation zone after 28 days of culture. ii) The viability of the root tips of five plants per treatment was determined by using nitro blue tetrazolium salts (NBT, Sigma-Aldrich), according to Connolly and Berlyn (1996). The percentage of active apices of the tap roots and of the most developed laterals was calculated 7, 14, 21 and 28 days after germination. The length of NBT stained apices of the tap roots was measured with an ocular micrometer scale. iii) The structure of the apical meristems and the localization of proliferating cells of the tap root apices were assessed on 21 and 28 days old plants. Root apex structure was analyzed on median longitudinal sections (MLSs), stained with toluidine blue, of epon-araldite embedded samples processed according to the usual cytological techniques. Proliferating cells were localized through indirect immunofluorescence of 5-bromo-2'-deoxyuridine (BrdU, Sigma- Aldrich) on MLSs of root apices embedded in London Resin White (Sigma-Aldrich), according to the procedure described by Fusconi et al. (2007). BrdU was localized with an anti-mouse IgG Cy3-coniugated (SigmaAldrich) and sections were counterstained with 4',6-diamidino-2-phenilindole (DAPI, Sigma-Aldrich). All samples were observed with a Nikon Eclipse E400 (Nikon Corporation, Tokio, Japan) light microscope and images were acquired with a digital camera Nikon Ds-5M. Immunostained sections were observed with the same microscope equipped with epifluorescence; the UV2A and G2A filters were used for DAPI and Cy3, respectively. 


\section{Treatments with cadmium}

Tobacco is a known Cd-tolerant plant (Martins et al. 2011) and preliminary experiments showed that, using the above described $1 / 2$ MS medium, only very high $\mathrm{Cd}$ concentrations modified root system morphogenesis. Therefore, a poor MS nutrient medium was prepared in accord to Quaghebeur and Rengel (2003). Seeds of $N$. tabacum, sterilized as described above, were sown on Cd-free medium. After germination they were transferred to Petri dishes containing 0; $0.2 ; 2 ; 20 ; 50 \mu \mathrm{M}$ of cadmium chloride $(\mathrm{CdCl} 2$, Sigma-Aldrich) for further 21 days. Morphometric analysis (leaf area, tap root and total root length and degree of branching) were performed as previously described.

\section{Statistical analysis}

The data were expressed as means $\pm \mathrm{SE}$ and compared through the KruskalWallis oneway analysis of variance using the Systat 11 software for Windows; the differences were considered as statistically significant for $\mathrm{P}<0.05$.

\section{Results and discussion}

Tobacco plants grown on the $\mathrm{P}+$ medium had larger and more numerous leaves and a higher total leaf area than those grown in P- conditions (Figs 1a-c); the leaf parameters increased regularly up to end of the experiment in both treatments (Fig. 1c and table I). The root-to-shoot dry weight ratio increased significantly in the P-plants in comparison to $\mathrm{P}+$ plants after 4 weeks of culture (table I) as frequently occurs when plants grow under Pi starvation conditions (Ramaekers et al. 2010). These results thus pointed to a "normal" growth response of tobacco plants to Pi availability, despite the in vitro growth conditions used for this work. The root system of $N$. tabacum consisted of a tap root that branched mostly in its upper part (Figs 1a, b). The length of the whole root system was higher, by about $35 \%$, at the end of the experiment in the P-plants (Fig. 1d). The tap root length of the P-plants increased linearly; on the contrary lengthening declined after 14 days of culture in the $\mathrm{P}+$ treatment and was very low between 21 and 28 days of culture (Fig. 1e). The number of lateral roots was significantly higher in the P+ plant at the end of the experiment (Table I) and the degree of branching of the tap root was significantly higher in $\mathrm{P}+$ plants from 14 days onwards (Fig. 1f). Root system of tobacco, therefore, responded to Pi availability differently from that of Arabidopsis, where shorter and more branched primary roots were found in response to low Pi (López-Bucio et al. 2002; Sánchez-Calderón et al. 2005). Since root growth depends on cell elongation and root apex activity, we determined the 
length of the cortical cells, as well as root apex morphology and activity in Pistarved and Pisufficient tobacco plants (table II; Fig. 2). These analyses showed that, at the end of the experiment, the fully elongated cortical cells were about $9 \%$ shorter in the $\mathrm{P}+$ plants than in the $\mathrm{P}$ - plants $(132.62 \pm 2.48$ and $145.77 \pm 2.59$ $\mu \mathrm{m}$, respectively). Root apices of the tap root and of the most developed laterals of P-plants generally had progressively longer root hairs, starting from the root apex base shootwards (Fig. 2a) and stained intensely with NBT (Fig. 2b, Table II) showing to be metabolically active. Instead, in the P+ treatment, most apices showed fully elongated root hairs close to the root tip (Fig. 2c) and were metabolically inactive, being slightly or not stained by NBT (Fig. 2d, Table II). The mean length of the $\mathrm{P}+$ apices of the tap roots increased up to 14 days from germination thereafter attaining a mean length sensibly shorter than that of Pplants which instead lengthened up to the 3rd week of culture (Table II). These findings led us to conclude that root shortening in the $\mathrm{P}+$ plants was mostly dependent on the reduced meristem activity, as the slight decrease of cortical cell length may have influenced root length only to a small extent. Observations on MLSs confirmed that in P-plants almost all the apices were active as they showed a normal organization of the meristem and a well developed and pointed root cap (Fig. 2e, e'); labeled nuclei were evenly distributed in the cortex and central cylinder meristems, apices had a defined quiescent centre and labeled initials of the root cap (Figs 2f, f'). On the contrary, in the P+ plants most apices were inactive. They frequently had vacuolated initial cortex cells and a reduced root cap (Fig. 2g). Moreover, proliferative activity decreased in most apices from 21 days onwards and about $25 \%$ of the apices almost completely lacked BrdU labeled nuclei, and were hence differentiated, 28 days from germination (Figs $2 \mathrm{~h}$, h'). Interestingly, the cytological alterations occurring in the root apices of tobacco under high Pi were quite similar to those leading to determinate primary root growth under low Pi in Arabidopsis (Sánchez-Calderón et al. 2005). These different responses are difficult to explain. In Arabidopsis root morphogenesis has been deeply analyzed in the last years and an important role of auxin transport and sensitivity has been recognized in the responses to Pi starvation (PérezTorres et al. 2008; Chiou and Lin 2011; Miura et al. 2011). On the contrary there is insufficient literature, if any, on the role of auxin metabolism in tobacco, in relation to Pi availability. Differences in IAA levels (Torelli et al. 2000) and in the expression of genes involved in auxin biosynthesis and signaling ( $\mathrm{Li}$ et al. 2012) were found between Pi-starved and Pi-sufficient plants of Allium porrum and Zea mays, respectively. Because both plants, like tobacco, exhibit increased root length and decreased branching in low Pi conditions (Trotta et al. 1991; Li et al. 2012), these results point to a general 
role of auxin in the morphogenetic responses of the root system to low $\mathrm{Pi}$ conditions. Auxin has also been shown to be strictly involved in the SIMR induced by toxic elements (Potters et al. 2007; 2009; Hu et al. 2013). In tobacco, as generally occurs, $\mathrm{Cd}$ reduced plant growth and modified root system morphogenesis (Fig. 3a). Leaf area was significantly decreased by $20 \mu \mathrm{M} \mathrm{Cd}$, and was drastically reduced by $50 \mu \mathrm{M} \mathrm{Cd}$ (Fig 3b). The total root growth and the lengthening of the tap roots were significantly inhibited by $2 \mu \mathrm{M} \mathrm{Cd}$, and this inhibition was concentration-dependent, the tap root lengthening being almost completely blocked by the highest concentrations of Cd (Figs 3c, d). Although $\mathrm{Cd}$ reduced tap root length, the formation of new lateral roots was less affected $(10.57 \pm 0.48$ and $10.59 \pm 0.54$ in controls and $50 \mu \mathrm{M}$ treated plants, respectively, after 21 days of treatment), thus resulting in higher tap root branching (Fig 3e). Treatment of tobacco plants with relatively high concentrations of $\mathrm{Cd}$ thus led to a typical SIMR, which has been interpreted as a way to limit stress exposure. In Arabidopsis, Cd treatment decreases the level of auxin near the primary root tip, causing a block of meristem cell division and root growth, whilst auxin increases in the middle and upper zone of the root were lateral roots form (Potters et al. 2007). A similar mechanism could be active in the Cd-treated tobacco plants analyzed in the present work. Indeed, redistribution of auxin seems to generally occur after $\mathrm{Cd}$ treatment, as recently shown also in rice plants treated with $\mathrm{Cd}$ (Zhao et al. 2012). In conclusion, the above data indicate that while the SIMR phenotype is similar in tobacco and Arabidopsis, Pi-deficiency gives rise to a root morphogenesis which changes from species to species. This may be related to the different strategies that plants have evolved to acquire Pi. In Arabidopsis the reprogramming of root development under Pi deprivation leads to a shallow and superficial root system to optimize the absorption of $\mathrm{Pi}$, which is usually more abundant near the soil surface (Vance et al. 2003; Hammond and White 2008). Tobacco under Pi-deficiency instead lengthens its roots to enhance the possibility to encounter zones of high Pi availability (Ramaekers et al. 2010) and reduces branching probably to limit the cost of soil exploration. These contrasting responses to $\mathrm{Pi}$ availability may also rely on the different dependency of plant species on arbuscular mycorrhizal (AM) symbiosis. This is a wide-spread symbiosis between the roots of most land plants and Glomeromycota fungi where the fungus assists the host plant in acquiring nutrients, mainly $\mathrm{Pi}$, from the soil (Smith and Read 2008; Perotto et al. 2013). Tobacco, differently from Arabidopsis, is an AM-host plant. It is thus tempting to speculate that the root architecture typical of tobacco (and other mycorrhizal host plants) under low Pi conditions may positively influence the colonization process. The finding that the production of strigolactones, which favour colonization by inducing AM hyphal branching (Akiyama et al. 2005), increases in Pi-starved plants (see Yoneyama et al. 2012) and that strigolactones modify root morphogenesis (Ruyter-Spira et al. 2011; 
Arite et al. 2012) through changes in the regulation of auxin efflux (Koltai et al. 2010) supports the notion of a tight correlation between root morphogenesis under low $\mathrm{Pi}$ and the colonization process.

\section{Acknowledgements}

This work was funded by the Italian MURST under grant 2007PKFAAT.

\section{References}

Akiyama K, Matsuzaki K, Hayashi H. 2005. Plant sesquiterpenes induce hyphal branching in arbuscular mycorrhizal fungi. Nature 435: 824-827.

Akhtar MS, Oki Y, Adachi T. 2009. Mobilization and acquisition of sparingly soluble P-sources by Brassica cultivars under P-starved environment II. Rhizospheric $\mathrm{pH}$ changes, redesigned root architecture and Pi-uptake kinetics. J Integr Plant Biol 51: 1024-1039.

Arite T, Kameoka H, Kyozuka J. 2012. Strigolactone positively controls crown root elongation in rice. J. Plant Growth Regul 31: 165-172.

Barlow PW. 2010. Plastic, inquisitive roots and intelligent plants in the light of some new vistas in plant biology. Plant Biosyst 144: 396-407.

Chiou TJ, Lin SI. 2011. Signaling network in sensing phosphate availability in plants. Annu Rev Plant Biol 62: 185-206.

Connolly JH, Berlyn GP. 1996. Cytochemical assay for differential respiratory activity in roots and root hairs. Biotechnol Histochem 71: 197-201.

Den Herder G, Van Isterdael G, Beeckman T, De Smet I. 2010. The roots of a new green revolution. Trends Plant Sci 15: 600-607.

Fusconi A. 2014. Regulation of root morphogenesis in arbuscular mycorrhizae: what role do fungal exudates, phosphate, sugars and hormones play in lateral root formation? Ann Bot 113: 19-33.

Fusconi A, Gallo C, Camusso W. 2007. Cadmium effects on root apical meristems of Pisum sativum L. Viability, cell proliferation, microtubule pattern as suitable markers for stress pollution assessment. Mutat Res (Gen Tox Environ Mutag) 632: 9-19.

Garg N, Bhandari P. 2013. Cadmium toxicity in crop plants and its alleviation by arbuscular mycorrhizal (AM) fungi: An overview. Plant Biosyst in press.

Hammond JP, White PJ. 2008. Sucrose transport in the phloem: integrating root responses to phosphorus starvation. J Exp Bot 59: 93-109.

Hattab S, Chouba L, Ben Kheder M, Mahouachi T, Boussetta H. 2009. Cadmium- and copperinduced DNA damage in Pisum sativum roots and leaves as determined by the Comet assay. Plant Biosyst 143: S6-11.

Hu YF, Zhou G, Na XF, Yang L, Nan WB, Liu X, Zhang YQ, Li JL, Bi YR. 2013. Cadmium interferes with maintenance of auxin homeostasis in Arabidopsis seedlings. J Plant Physiol 170: 965-975. 
Koltai H, Dor E, Hershenhorn J, Joel DM, Weininger S, Lekalla S, Shealtiel H, Bhattacharya C, Eliahu E, Resnick N, Barg R, Kapulnik Y. 2010. Strigolactones' effect on root growth and root-hair elongation may be mediated by auxin-efflux carriers. J Plant Growth Regul 29: 129-136.

Li Z, Xu C, Li K, Yan S, Qu X, Zhang J. 2012. Phosphate starvation of maize inhibits lateral root formation and alters gene expression in the lateral root primordium zone. BMC Plant Biol 12: 89105.

López-Bucio J, Hernández-Abreu E, Sánchez-Calderón L, Nieto-Jacobo MF, Simpson J, HerreraEstrella L. 2002. Phosphate availability alters architecture and causes changes in hormone sensitivity in the Arabidopsis root system. Plant Physiol 129: 244-256.

Malamy JE. 2005. Intrinsic and environironmental response pathways that regulate root system architecture. Plant Cell Environ 28: 67-77.

Martins LL, Mourato MP, Cardoso AI, Pinto AP, Mota AM, Goncalves MDS, de Varennes A. 2011. Oxidative stress induced by cadmium in Nicotiana tabacum L.: effects on growth parameters, oxidative damage and antioxidant responses in different plant parts. Acta Physiol Plant 33: 13751383.

Miura K, Lee J, Gong Q, Ma S, Jin JB, Yoo CY, Miura T, Sato A, Bohnert HJ, Hasegawa PM. 2011. SIZ1 regulation of phosphate starvation-induced root architecture remodeling involves the control of auxin accumulation. Plant Physiol 155: 1000-1012.

Pérez-Torres CA, López-Bucio J, Cruz-Ramírez A, Ibarra-Laclette E, Sunethra Dharmasiri S, Estelle M, Herrera-Estrella L. 2008. Phosphate availability alters lateral root development in Arabidopsis by modulating auxin sensitivity via a mechanism involving the TIR1 auxin receptor. Plant Cell 20: 3258-3272.

Perotto S, Angelini P, Bianciotto V, Bonfante P, Girlanda M, Kull T, Mello A, Pecoraio L, Perini C, A. Persiani AM, Saitta A, Sarrocco S, Vannacci G, Venanzoni R, Venturella G, 11 Selosse MA. 2013. Interactions of fungi with other organisms. Plant Biosyst 147: 208- 218.

Potters G, Pasternak TP, Guisez Y, Palme KJ, Jansen MAK. 2007. Stress-induced morphogenic responses: growing out of trouble? Trends Plant Sci 12: 98-105.

Potters G, Pasternak TP, Guisez Y, Jansen MAK. 2009. Different stresses, similar morphogenetic responses: integrating a plethora of pathways. Plant Cell Environ 32: 158-169.

Quaghebeur M, Rengel Z. 2003. The distribution of arsenate and arsenite in shoots and roots of Holcus lanatus is influenced by arsenic tolerance and arsenate and phosphate supply. Plant Physiol 132: 1600-1609.

Ramaekers L, Remans R, Rao IM, Blair MW, Vanderleydena J. 2010. Strategies for improving phosphorus acquisition efficiency of crop plants. Field Crops Res 117: 169-176.

Ruyter-Spira C, Kohlen W, Charnikhova T, van Zeijl A, van Bezouwen L, de Ruijter N, Cardoso C, Lopez-Raez JA, Matusova R, Bours R, Verstappen F, Bouwmeester H. 2011. Physiological effects of the synthetic strigolactone analog GR24 on root system architecture in Arabidopsis: another belowground role for strigolactones? Plant Physiol 155: 721-734. 
Sánchez-Calderón L, López-Bucio J, Chachón-López A, Cruz-Ramirez A, Nieto-Jacobo F, Dubrowsky JG, Herrera-Estrella L. 2005. Phosphate starvation induces a determinate developmental program in the roots of Arabidopsis thaliana. Plant Cell Physiol 46: 174-184.

Sanità di Toppi L, Gabbrielli R. 1999. Response to cadmium in higher plants, Environ Exp Bot 41: $105-130$.

Smith SE, Read DJ. 2008. Mycorrhizal symbiosis. 3rd ed, San Diego, CA: Academic Press. Torelli A, Trotta A, Acerbi L, Arcidiacono G, Berta G, Branca C. 2000. IAA and ZR content in leek (Allium porrum L.) as influenced by $\mathrm{P}$ nutrition and arbuscular mycorrhizae, in relation to plant development. Plant Soil 226: 29-35.

Trotta A, Carminati C, Schellenbaum L, Scannerini S, Fusconi, Berta G. 1991. Correlation between root morphogenesis, VA mycorrhizal infection and phosphorus nutrition. In: McMichael BL, Person H, eds. Plant Roots and their Environironment. Amsterdam: Elsevier. p 333-339.

Vance CP, Uhde-Stone C, Allan DL. 2003. Phosphorus acquisition and use: critical adaptation by plants for securing a non-renewable resource. New Phytol 157: 423-447.

Yoneyama K, Xie X, Kim HI, Kisugi T, Nomura T, Sekimoto H, Yokota T, Yoneyama K. 2012. How do nitrogen and phosphorus deficiencies affect strigolactone production and exudation? Planta 235: 1197-1207.

Zhao FY, Han MM, Zhang SY, Wang K, Zhang CR, Liu T, Liu W. 2012. Hydrogen peroxidemediated growth of the root system occurs via auxin signaling modification and variations in the expression of cell-cycle genes in rice seedlings exposed to cadmium stress. J Integr Plant Biol 54: 991-1006. 
Table I. Ponderal and morphometric parameters of Nicotiana tabacum plants grown in low and high-phosphate conditions, 28 days after germination.

\begin{tabular}{|l|l|l|l|}
\hline & $\mathrm{P}+$ & $\mathrm{P}-$ & $\mathrm{P}<0.05$ \\
\hline Shoot dry weight $(\mathrm{mg})$ & $11.08 \pm 0.75$ & $6.98 \pm 0.25$ & $*$ \\
\hline Root dry weight $(\mathrm{mg})$ & $3.78 \pm 0.38$ & $4.56 \pm 0.58$ & - \\
\hline $\begin{array}{l}\text { Root-to-shoot ratio } \\
(\mathrm{mg} / \mathrm{mg})\end{array}$ & $0.34 \pm 0.02$ & $0.65 \pm 0.07$ & $*$ \\
\hline Leaf number & $6.50 \pm 0.31$ & $4.07 \pm 0.27$ & $*$ \\
\hline Lateral root number & $13.36 \pm 0.79$ & $10.50 \pm 0.64$ & $*$ \\
\hline
\end{tabular}

Table II. Percentage of active apices and root apex length in Nicotiana tabacum plants grown in low and high-phosphate conditions. * indicates significant differences between treatments.

\begin{tabular}{|l|l|l|l|}
\hline & $\mathrm{P}+$ & $\mathrm{P}-$ & $\mathrm{P}<0.05$ \\
\hline Shoot dry weight $(\mathrm{mg})$ & $11.08 \pm 0.75$ & $6.98 \pm 0.25$ & $*$ \\
\hline Root dry weight $(\mathrm{mg})$ & $3.78 \pm 0.38$ & $4.56 \pm 0.58$ & - \\
\hline $\begin{array}{l}\text { Root-to-shoot ratio } \\
\text { (mg/mg) }\end{array}$ & $0.34 \pm 0.02$ & $0.65 \pm 0.07$ & $*$ \\
\hline Leaf number & $6.50 \pm 0.31$ & $4.07 \pm 0.27$ & $*$ \\
\hline Lateral root number & $13.36 \pm 0.79$ & $10.50 \pm 0.64$ & $*$ \\
\hline
\end{tabular}




\section{Figures}

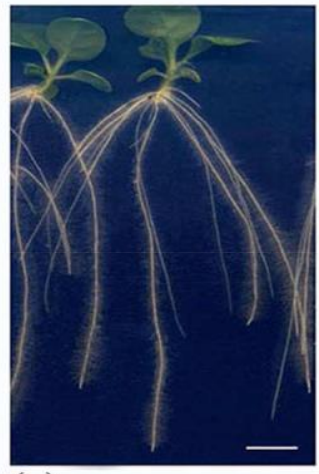

(a)

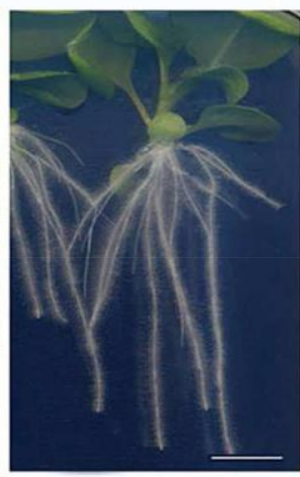

(b)
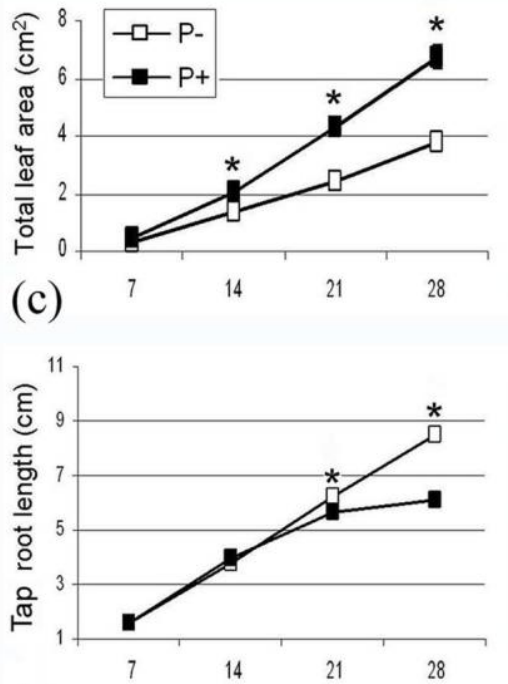

(e)
Days from germination
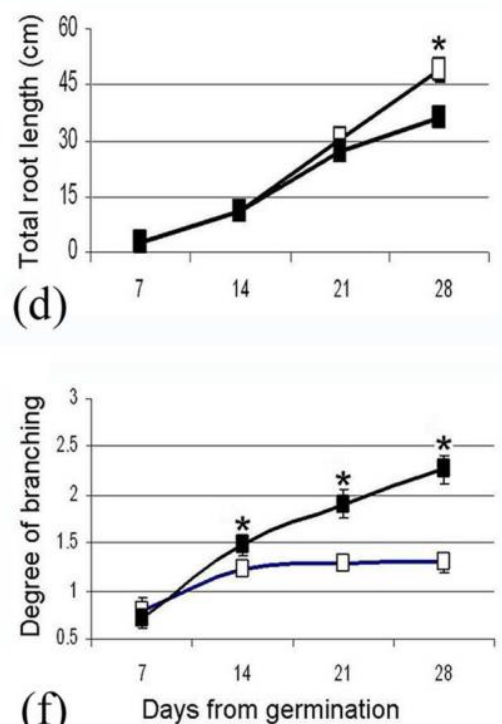

(f)

Days from germination

Figure 1. Effects of Pi availability on Nicotiana tabacum plant development. (a, b) Scanned tobacco plants grown for 28 days on the surface of agar plates containing low (a) and high (b) Pi media. Bars, $1 \mathrm{~cm}$. (c-f) Morphometric parameters related to leaf and root growth. Average values $( \pm \mathrm{SE})$ are given for the total leaf area per plant (c), the total (d) and the tap (e) root length, the degree of the tap root branching (f). * indicates significant differences between treatments. 

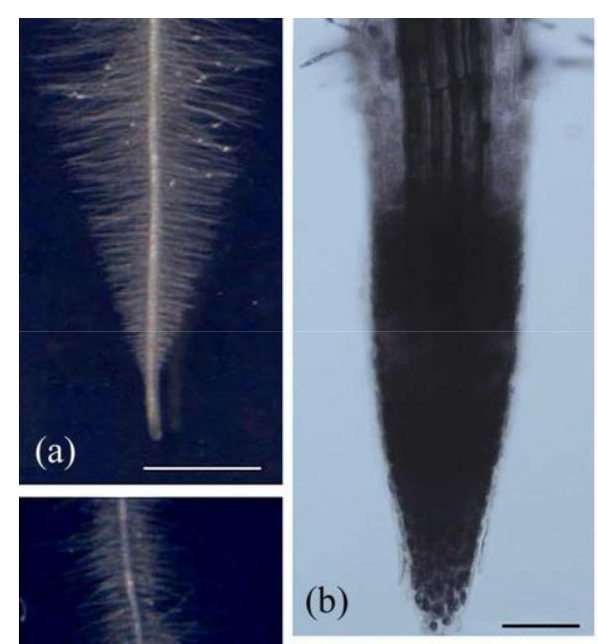

(b)
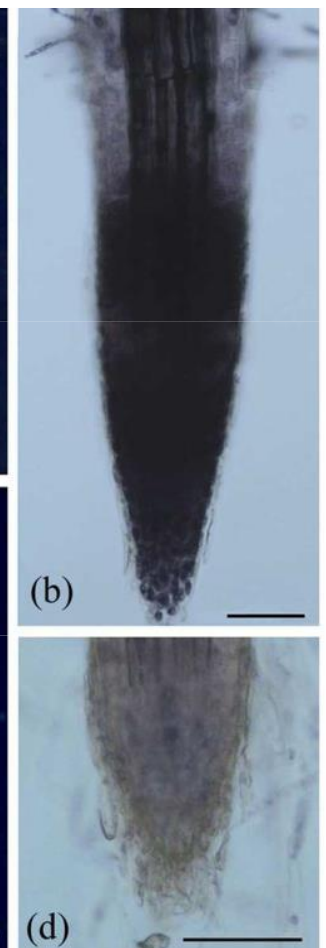

(c)

(d)
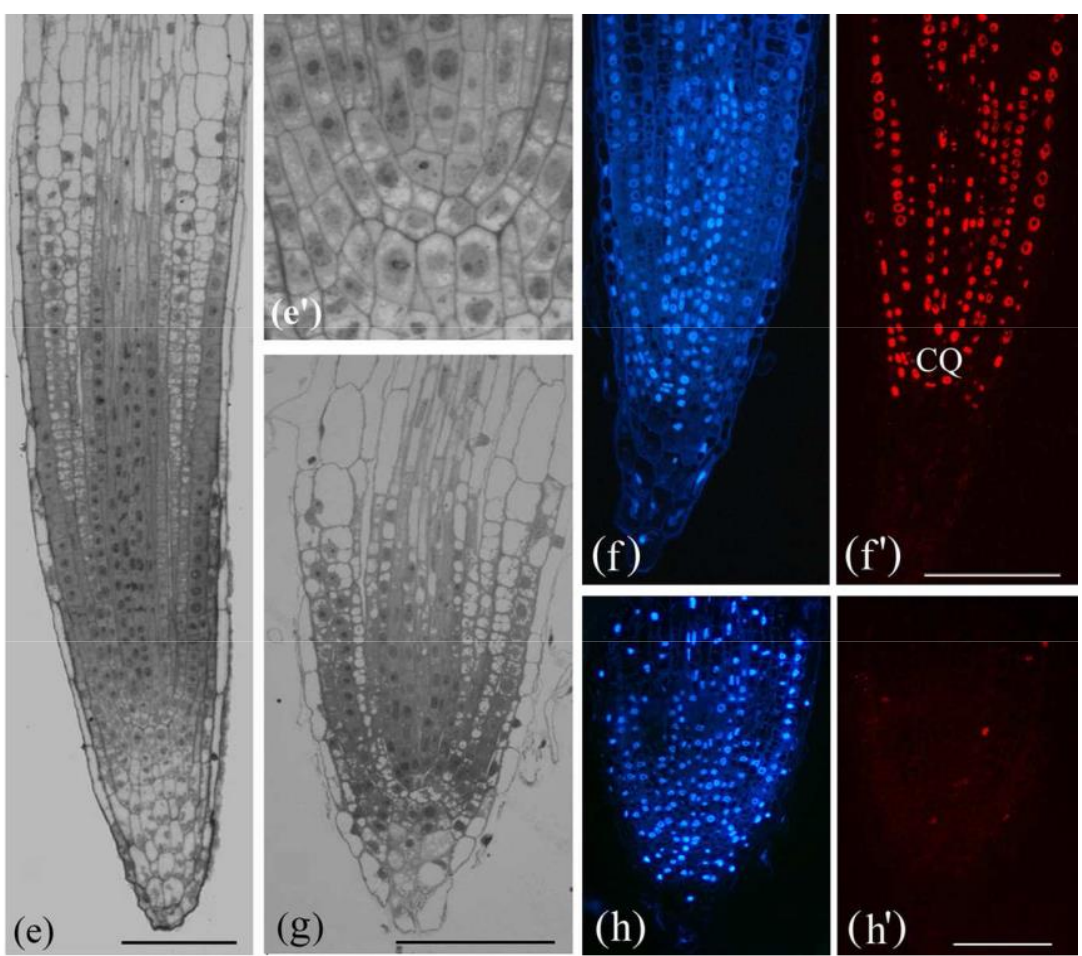

Figure 2. Representative images showing the root tips of the tap roots of Nicotiana tabacum plants grown in low (a, b, e-e', f-f') and high (c, d, g, h-h') Pi media, for 28 days from germination. (a, c), Root tips and root hairs of the tap roots. Bars, $1.5 \mathrm{~mm}$. (b, d) Root tips stained with NBT. (e, g) Longitudinal median semi-thin sections (e', magnification of the initial zone of e). (f-f', h-h') Effects of Pi availability on the cell proliferation of the root apices; (f, h), DAPI-stained sections showing all nuclei, (f'-h') indirect immunofluorescence showing the nuclei of proliferating cells (CQ, quiescent centre). (b, d- h') Bars, $100 \mu \mathrm{m}$. 

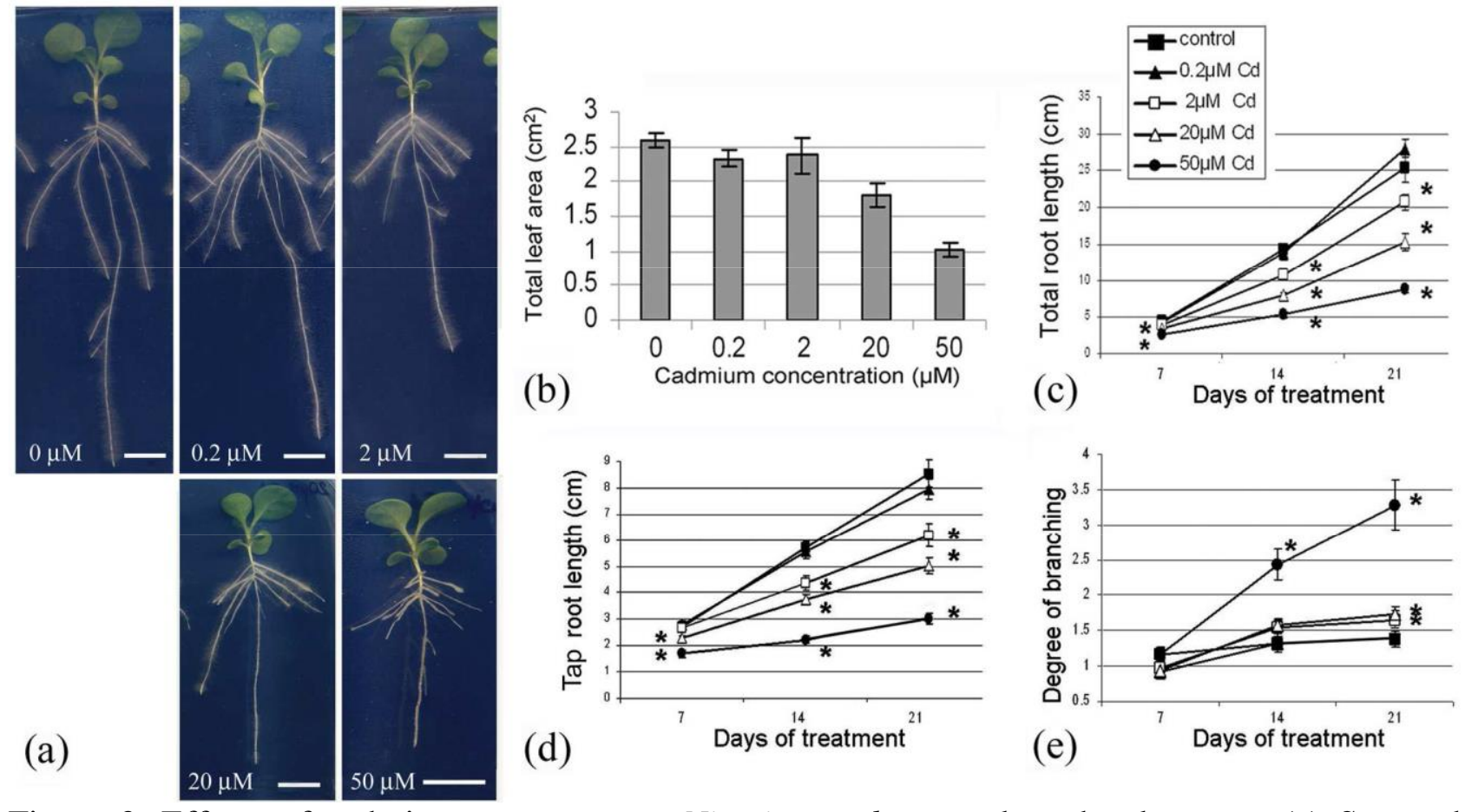

Figure 3. Effects of cadmium treatment on Nicotiana tabacum plant development. (a) Scanned tobacco plants grown for 21 days on the surface of agar plates of controls $(0 \mu \mathrm{M})$ and containing 0.2 ; 2; 20 and $50 \mu \mathrm{M} \mathrm{CdCl}_{2}$. Bars, $1 \mathrm{~cm}$. (b-e) morphometric parameters related to leaf and root growth. Average values $( \pm \mathrm{SE})$ are given for the total leaf area per plant (b), the total (c) and the tap (d) root length, the degree of the tap root branching $(\mathrm{e}) . *$ indicates significant differences in comparison with controls. 